\title{
Status and Perspectives in Overlaying under Particular Consideration of Sophisticated Welding Processes*
}

by Stephan Alfred Egerland**

\begin{abstract}
Surfacing is an indispensable measure both to conserve as well as to generate worth. Different welding methods have been created over the time, were established and have found their long-term utilization in numerous specific industrial applications. This paper is intended to basically focus on some of the most important overlay welding processes and an evaluation of most recent process developments and advancements respectively, standing for remarkable improvements in terms of weld quality and reproducibility. The emphasis should thereby being laid upon the fully mechanized Gas Shielded Tungsten Arc (Hot wire) Welding (GTAW) and the Gas Shielded Metal Arc Welding (GMAW). Especially the usage of the highly advanced Cold Metal Transfer Process (CMT) enables the user to achieve new levels in process stability and quality, also in the field of overlaying.
\end{abstract}

Key Words: Surfacing, Weld Overlay, GTAW-Hot wire, GTAW-Twin Wire, Sophisticated GMAW, Cold Metal Transfer Process

\section{Introduction}

About $98 \%$ of all welding applications are estimated to refer to fusion welding. The remaining amount belongs to the group of surfacing, which includes a row of different special operations as e.g. hardfacing, or weld cladding. The technological background for achieving high quality overlay welds is most interesting. Herein it is intended to lay a focus upon the "corrosion driven" segment and the endeavors to improve the conditions in applications relating to this field. Mainly Submerged- and Open Arc processes are used in order to meet these requirements in a widest extent. Submerged Arc Welding Processes (SAW or RESW) are providing specific benefits e. g. high weld deposition rates. Nonetheless it must be mentioned that they have particular drawbacks as e. g. restricted opportunities for direct weld pool control or the use of flux itself which naturally restricts the processes, as well as their equipment requires higher capital costs. Due to even these restrictions the role of the open arc cladding processes has achieved a considerable importance. Benefits as universality in handling and suitability both in the shop and on-site as likewise an easy and accurate adjustability of metallurgical issues in coherence with economically acceptable process efficiencies are reasons to use sophisticated open arc cladding processes. Two of those, the semi-automated Gas Shielded Tungsten Arc (Hot wire) Welding (GTAW) and the Gas Shielded Metal Arc Welding (GMAW) shall be treated hereinafter.

\footnotetext{
${ }^{*}$ Received: 2008.11.18

${ }^{* *}$ FRONIUS International GmbH, Wels, Austria
}

\section{Sophisticated Open Arc Cladding Processes}

\subsection{GTAW Hot wire Cladding on Off-Shore Components}

Representative applications may be found e. g. in the field of power generation both fossil and nuclear, or natural resources exploitation. Wear resistant base materials as e. g. AISI 8630 or AISI 4130, are parent metals with the latter for manufacturing complex geometric casting components, as gate valves or separators used for process flow control systems in the gas/oil and off-shore industry, see also Figure 1.
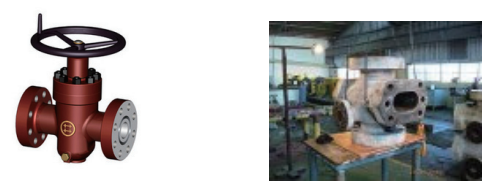

Fig. 1 Typical Off-Shore Valve (left) and Casting Component prior to Cladding (right) (1)

Specific areas of these components - in particular the bores are subjected by an often severe combination of both corrosion and mechanical wear. To overcome these high-grade material influencing effects a weld overlay is deposited on the susceptible areas. Surprisingly Shielded Metal Arc Welding (SMAW) can be found very often being used for manually cladding of high pressure component bores as described above. This low efficient process often allows the only access to smaller diameter- and complex bores. The latter however leads to another problem. Figure 2 shows a view into an off-shore valve component's bore, clad by using SMAW. A great amount of "needless" weld metal has to be removed subsequently by machining. The problem is doubled due to firstly the needed time to deposit the costly weld metal and secondly the subsequent efforts to remove this needless 
weld metal again off the bore to achieve the required geometry and surface quality. Similar issues are known with larger bore diameters where SAW Cladding is often used for. Even though the accuracy in depositing the weld metal may be improved, the issues of removing often unnecessarily deposited weld metal from the bore's surface are yet remaining. Advanced open arc processes however do have the capability to improve the situation both in precise weld metal depositing and a considerably machining time reduction.
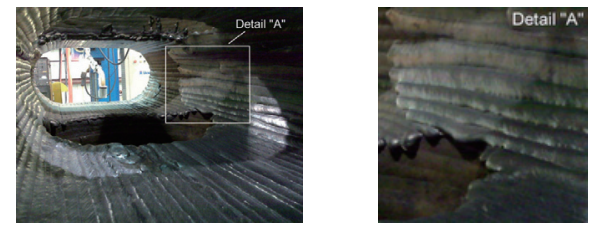

Fig. 2 View into an SMAW clad bore and detail of the clad surface of an off-shore valve component (2)

GTAW Hot wire Cladding is one of the most reliable and approved processes in this relation. Its principle is based on the combination of a high quality welding process and an efficiency increase by using an inductively heated filler wire. An additional "Hot wire Power-Supply", providing limited voltage to avoid an arc ignition also at higher "pre-heating currents", is used for pre-heating the filler material. Hereby the actual GTAW arc power can be reduced, to mitigate the fusion depth and thus, to reduce the dilution. Another fundamental time consuming factor in cladding operations with off-shore components is the adjustment of the work piece in relation to the welding torch prior to, and while welding, which is the reason for that SMAW often appears to be the only alternative. The weldor can adjust both electrode handling as welding parameters in relation to the bore geometry requirements. To improve the economical output and the clad layer quality itself, also with complex or narrow bore geometries, sophisticated welding systems must combine both most optimized welding processes and highly advanced welding process control. Figure 3 shows schematically a GTAW hot wire Cladding system consisting of different tailored electronic and mechanical components. The process control unit (A) is in charge for containing and adjusting all important information in regard to the cladding application to be performed. Bore geometries different to rotational symmetric ones, see also Figure 4, are hereby feasible to be processed. Beneficial with this system is the torch movement relative to the stationary component to be welded. All this however, continuously in relation to the torchand work piece positions and without the necessity to newly adjust the torch position each time after a single layer has been completed.

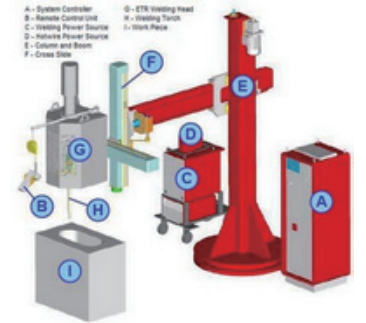

Fig. 3 Schematic Representation of Endless Torch Rotating (ETR) GTAW Cladding System (2)

The implementation of a so-called "Arc Voltage Control" assures precise torch stand-off. Adjusted welding parameters are thus used and controlled in a very narrow range.

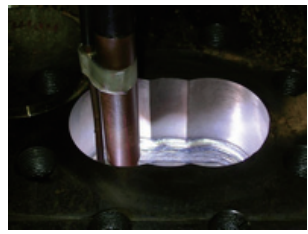

Fig. 4 Specific Off-Shore Component Bore GTA Hotwire Cladding Operation (2)

As good as highly advanced GTAW Hot wire cladding is suitable for intricate applications, the economical process efficiency in terms of weld deposition rates is rather low. To overcome the lack of efficiency an increase of the weld metal deposition rate by increasing the added filler amount may be evaluated as a feasible solution. As to be seen in Table 1 showing a comparison between single- and twin hot wire GTAW cladding process performance - it is possible to rise the weld deposition rate considerably by using two filler wires instead of one.

Table 1 GTAW single- and twin hot wire cladding performance overview (2)

\begin{tabular}{|c|c|c|c|}
\hline \multicolumn{2}{|l|}{ Single Wire } & \multicolumn{2}{|l|}{ Twin Wire } \\
\hline Wire Diameter (mm) & $1.0-1.2$ & Wire Diameter (mm) & 1.2 \\
\hline $\begin{array}{l}\text { Weld deposition rate } \\
\qquad(\mathrm{kg} / \mathrm{h})\end{array}$ & & $\begin{array}{l}\text { Weld deposition rate } \\
\qquad(\mathrm{kg} / \mathrm{h})\end{array}$ & \\
\hline Position PC & $1.7 \leq 2.2$ & Position PC & $\sim 3.0$ \\
\hline Position PA & $\sim 4.0$ & Position PA & $\sim 5.0$ \\
\hline $\begin{array}{l}\text { Welding Speed } \\
(\mathrm{cm} / \mathrm{min})\end{array}$ & $\sim 40$ & $\begin{array}{l}\text { Welding Speed } \\
\qquad(\mathrm{cm} / \mathrm{min})\end{array}$ & $\sim 70-75$ \\
\hline $\begin{array}{c}\text { Clad Layer Thickness } \\
(\mathrm{mm})\end{array}$ & $\sim 2.8$ & $\begin{array}{l}\text { Clad Layer Thickness } \\
\text { (mm) }\end{array}$ & $\sim 2.8$ \\
\hline Dilution (\%) & $5-10$ & Dilution (\%) & $5-10$ \\
\hline
\end{tabular}


This to perform specific hardware e.g. welding torches, has been developed, see also Figure 5.
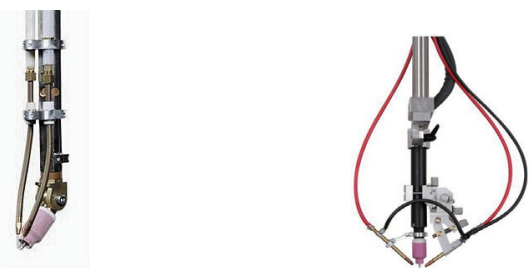

Fig. 5 Especially Developed Twin Wire Welding Torches for GTA Hotwire Cladding Applications (2)

GTAW Hot wire cladding both single and twin wire enables the user to meet either highest quality and process efficiency requirements. Hence, semi-automated GTAW Hotwire Cladding may enable both excellent quality properties and result repeatability as well as being an interesting alternative to other, e.g. Submerged Arc, weld cladding processes. Figure 6 shows finally different GTAW hot wire cladding results with interior and exterior use, respectively.
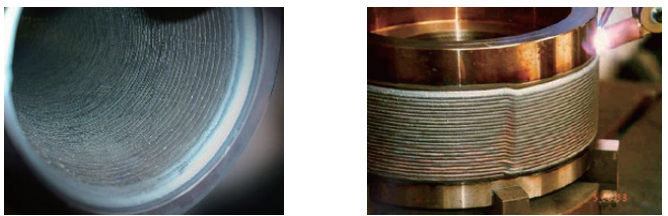

Fig. 6 Interior (left) and exterior (right) GTAW Hotwire cladding applications on off-shore components (2)

\subsection{GMAW-P Cladding Waste Incinerator Superheater Tubes}

The demand to improve quantity without sacrificing quality is a fundamental driving force with high level weld cladding. GMAW may have - generally seen - well-known economical advantages compared to GTAW. The relative insensitivity against changes in the torch stand off - e.g. due to work piece tolerances - as well as improved maintenance conditions may be stated as being generally beneficial. As a fairly representative example for how the usage of advanced GMAW may improve both weld quality and quantity an application from the power generation field should be explained hereinafter in greater detail. As well-known it is feasible meanwhile to control the GMAW process conditions, in particular the stability of the droplet detachment behavior, by highly advanced welding power supplies. A likely most well-known droplet transfer mode in this regard is quite certainly the Pulsed Arc Mode suitable for a wide application range due to the capability to tailor the pulse parameters in relation to the filler material used. GMAW-P can thus be seen as a higher efficient alternative to GTAW Hotwire cladding but achieving nonetheless similar quality level weld results. An interesting field GMAW-P cladding is used is the field of conventional power generation, i.e. boiler vessels and their components. As a particular one the manufacturing of boiler vessels for Waste Incinerator Plants can be mentioned. These facilities, used to gain energy by the incineration of waste, are also known as "Waste to Energy" (WTE) Plants.

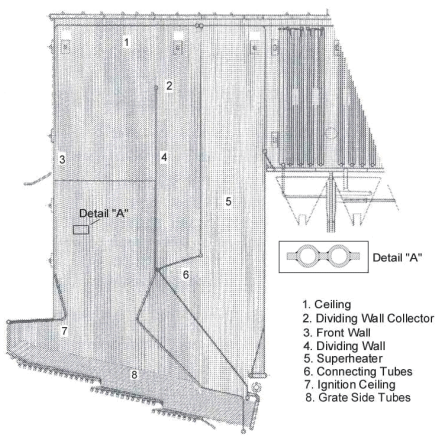

Fig. 7 Potential Cladding Applications within a Waste Incineration Boiler and transversal cross section of a Panel-Wall Structure (Note Detail “A”). (4)

Figure 6 is showing the different potential cladding applications within a waste incinerator boiler vessel. The vessel components are consisting of low alloyed and low heat resistant steels and must be cladded by using specific Nickel-Base alloys, see also Table 2, having both excellent corrosion- and heat resistance. As a most reliable filler material «ALLOY 625» (AWS A5.14 E NiCrMo-3) proved excellent behaviour under operating conditions both in corrosion- and temperature resistance

Table 2 Typical Composition of some important nickel base alloys used for GMAW cladding applications on waste incinerator components

\begin{tabular}{|c|c|c|c|c|c|c|c|}
\hline Alloy & $\begin{array}{c}\mathrm{Ni}+(\mathrm{Co}) \\
\%\end{array}$ & $\begin{array}{c}\mathrm{Cr} \\
\%\end{array}$ & $\begin{array}{c}\mathrm{Mo} \\
\%\end{array}$ & $\begin{array}{c}\mathrm{Si} \\
\%\end{array}$ & $\begin{array}{c}\mathrm{Fe} \\
\%\end{array}$ & $\begin{array}{c}\mathrm{W} \\
\%\end{array}$ & $\begin{array}{c}\mathrm{Nb}+\mathrm{Ta} \\
\%\end{array}$ \\
\hline 625 & Balance & 20 & 8 & $\leq 0.50$ & $\leq 5.0$ & - & 3.15 \\
& & - & - & & & & 4.15 \\
\hline 686 & Balance & 20.4 & 16.2 & 0.02 & 0.36 & 3.94 & - \\
\hline $\begin{array}{l}5020 \mathrm{~h} \\
\mathrm{Mo}\end{array}$ & Balance & 21 & 12 & 0.5 & 12 & 2 & $\sim 0.6$ \\
\hline
\end{tabular}

Waste incinerator boiler vessel materials have to resist average temperatures by $\sim 430^{\circ} \mathrm{C}$. However, some vessel areas being subjected to even higher temperatures, e. g. the superheater tubes which have to resist temperatures by up to $\sim 550^{\circ} \mathrm{C}$. In combination with fillers different to «ALLOY 625», e.g. «ALLOY 686» (UNS N06686) or «5020h Mo ${ }^{\mathrm{TM}} »(\mathrm{UNS}$ N06650), having an improved corrosion- and temperature resistance. The superheater single tubes are clad by GMAW-P. Especially 
developed welding systems combining welding power supplies and mechanical devices making it feasible to clad the superheater tubes circumferentially in longitudinal direction, see also Fig. 7.
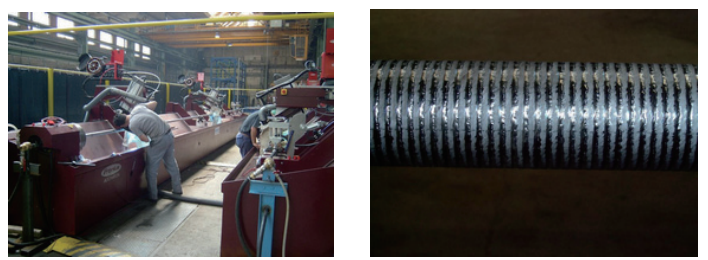

Fig. 8 Superheater Tube GMAW-P Clad System (left) and Surface of a clad Superheater Tube (right) (2)

Highly Nickel containing fillers can show a distinctive susceptibility for hot cracking, one reason for normally processing those materials by performing the stringer weld bead technique, used also for the superheater tube cladding. The weld is performed circumferentially - the tube is rotating underneath a stationary fixed but relative to the part, moving torch. Adjusting a spirally sideward offset of $\sim 50 \%$ a continuous overlapping and uniform layer thickness of $\sim 1 \mathrm{~mm}$ as well as a homogeneous clad layer surface can be obtained, see also Figure 8 (right). A narrow weld parameter window combined with precise values in welding speed and accurate torch positioning may lead to low dilution and clad layer iron contents of $\sim 5 \mathrm{wt}-\%$ in average. Additionally water cooling from the interior surface while welding prevents distortion, yielding the component's dimensional stability and additionally reduces the hot cracking risk. Nickel alloys, when melted, have a high surface tension. This again deteriorates both spherical droplet growth and droplet detachment behavior from the electrode tip towards the weld pool. However, it is important to achieve - at least approximately - the " 1 droplet per 1 pulse" condition. To improve the process stability special shielding gas compositions are used containing $\mathrm{Ar}+\mathrm{He}+\mathrm{CO}_{2}+\mathrm{H}_{2}$. $\mathrm{He}$ and $\mathrm{H}_{2}$ do increase thermal efficiency and improving the wetting behavior of the melt. The low amount of Carbon dioxide stabilizes the arc plasma. Droplet detachment behavior and process stability is improved by using these particular gas mixtures, but the heat input however, is increased what may be evaluated as a particular drawback. This appears deleterious in terms of the layer's corrosion resistance. According to [5] iron contents of $\max .10 \mathrm{wt}-\%$ in the layer shall be achieved to obtain a sufficient resistance. Figure 9 shows a transversal macro section of a weld coupon, generated by using GMAW-P with high a $30 \%$ Helium containing shielding gas.

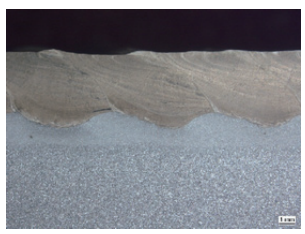

Fig. 9 «ALLOY 625» GMAW-P Clad Layer - Transversal Macro Cross Section (4)
It is recognizable in Figure 9 that the depth of fusion is high. Dilution and as a result of this the iron content of the clad layer are increased hereby. To overcome increasing iron contents often a second layer is required to be welded upon the first one when using GMAW-P Cladding. Iron contents of significantly below 5 wt- $\%$ may be obtained hereby. However, it must be mentioned herein that the GMAW-P process used for cladding waste incinerator boiler vessel superheater tubes is a fairly intricate undertaking due to all quality affecting parameters - in particular the electrode positioning in relation to the tube and the welding speed - to be controlled in a narrow range. Also the filler wire quality may significantly affect the clad layer quality. As reported already slight differences in the surface quality of the filler wire electrode can lead to significant deteriorations in the clad result. Especially lack of fusion by improper weld pool wetting behavior in general is reported to have been observed. This again makes certainly the GMAW-P cladding generally suitable for sensitive applications as e. g. superheater tube cladding, but nonetheless the process requires additional experience to be properly accomplished.

\subsection{Cold Metal Transfer (CMT) - State of the art in Weld Cladding}

WTE boiler vessels offer - besides the superheater tubes - an extended field for sophisticated GMAW cladding. The vessels consist in a great extent of conventional boiler steel «Panel Wall» Structures. "Detail A" in Figure 7. The CMT process was therefore tried out to substitute the conventional GMAW-P process previously used for these applications and to meet the stringent requirements as mentioned above (3). Conventional GMAW-P is based on using particular electrical parameters (voltage and current) for controlling the welding arc. CMT whereas is founded on a complete different and new concept of process control [(5), (6)] capable to avoid using the normal main process control parameter, the arc-voltage. Based on the short arc mode CMT controls the wire electrode in a way assuring that the forwards wire feed direction is reversed instantly backwards as the short circuit occurs between wire electrode and the weld pool to assist additionally the droplet detachment. Highest process stability correlating with a reduction of thermal energy input for reducing the fusion depth (dilution) is the result. As a fundamental and additional benefit the process sensitivity against tolerances could be significantly diminished which improves the user friendliness again in a great extent by reducing the additional adjustments through the operator. Hence the process meets the requirements in order to improve the entire cladding procedure. On the contrary to the superheater tubes, for CMT-cladding of 
waste incinerator panel walls the weaving- but not the stringer-weld bead technique is used. The major reason is of course to achieve higher productivity as unit area clad per unit time. Welding in vertical down position (Position PG acc. to EN 287) supports an additional reduction in fusion depth. Finally a peculiar 2-layer weaving sequence is conducted to achieve a uniform clad surface. Figure 10 (left) shows the characteristically oscillated surface of a CMT-welded panel-wall structure overlay, glass bead blasted after welding, and a characteristic CMT macro structure (right). Even though CMT is capable to create first layers having average iron contents fairly comparable to the second layer with conventional GMAW-P, i.e. significantly below the maximum iron content of $10 \mathrm{wt}-\%$, this special overlay structure is being executed. This due to the impacts on the clad surface are complex and rather to be seen as a combination of intricate corrosive and erosive effects. Considering the relatively low layer thickness of $\sim 1 \mathrm{~mm}$, the double layer structure provides a more sufficient amount of material to resist erosion whilst the incinerator components are in use. The homogenous average layer's thickness of $\sim 2 \mathrm{~mm}$ and the very low amounts of iron content in the CMT welded second layer ( $\sim 2 \mathrm{wt}-\%)$ lead finally to an increase of the vessel component efficiency.
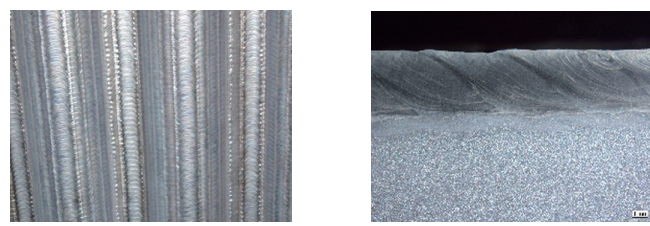

Fig. 10 Typical CMT vertical down welded «Alloy 625» clad surface appearance on a panel-wall and transversal macro section of an «Alloy 625» CMT overlay showing the characteristic uniform and low fusion depth (4)

The correlation between dilution and iron content has already been described. As explained, the CMT process is capable to generate a uniform low depth of fusion (Figure 10). What may be detected likewise is an additional reduction of weld pool motion, explainable by a reduced weld pool volume due to the frequent periodically and defined short circuit between wire electrode and molten pool. Due to this, CMT is most capable to be used for processing complex filler materials different to «Alloy 625» as e.g. «Alloy 686». This alloy contains higher amounts of Molybdenum which has a high segregation susceptibility. In other words, the usage of CMT may lead to a more homogeneous alloying element distribution within the weld deposit. This improves the alloy's corrosion resistance and thus again yields an additional component's efficiency increase. Figure 11 represents an «Alloy 686» CMT weld overlay micro section showing a very homogeneous weld metal with extremely low parent material's dilution.

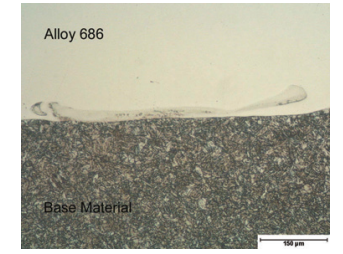

Fig. 11 Micro Section of a CMT welded «Alloy 686» Overlay (4)

\section{Conclusions}

Due to increasing demands from particular industrial fields weld cladding is an indispensable process used. In particular power generation or distribution and energy exploitation are requiring higher levels in both clad layer quality and output. Long-term approved welding processes as the Gas Shielded Tungsten Arc Welding and the Gas Shielded Metal Arc Welding and their peripheral equipment have been sophisticated and are used widely for weld cladding. A kind of quantum leap however is the Cold Metal Transfer (CMT) Process. CMT could be generally implemented for cladding so-called waste incinerator panel walls under use of «Alloy 625» filler material and achieves a yet unknown level of welding process stability, welding quality, result repeatability and last but not least user friendliness. All open-arc processes treated herein are an enormous asset for present and future cladding applications. By using the Cold Metal Transfer Process highest quality levels are obtainable without sacrificing cladding quality and most advanced filler metals, e.g. nickel base alloys, are future capable to be safely handled by this sophisticated process.

\section{References}

1) Shenkai Drilling Systems Shanghai, (http://www.shenkai.com)

2) FRONIUS International, Internal Investigations (unpublished)

3) "Merkblatt zur Durchführung und Prüfung von Auftragschweißungen an Rohrwänden von Kesselanlagen" (in German), VdTÜV-Merkblatt 1166 (12.2001), TÜV-Verlag Köln

4) S. Egerland, R. Helmholdt, "Overlaying (Cladding) of High Temperature Affected Components by using the Cold Metal Transfer Process" Proceedings of the IIW International Conference, Edited by P. Mayr, G. Posch, H. Cerjak, Verlag der Technischen Universität Graz, 2008

5) H. Hackl, K. Himmelbauer, "The CMT-Process - A Revolution in Welding Technology", IIW Doc. XII-1875-05

6) J. Bruckner, K. Himmelbauer," Potentially Areas of Use of the CMT-Process, notably in joining steel to aluminium", IIW Doc. XII-1846-05 